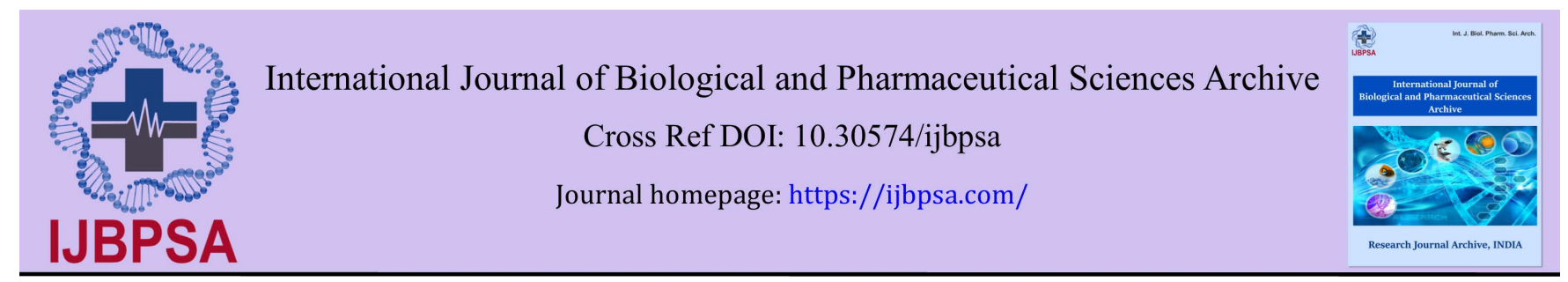

(REVIEW ARTICLE)

\title{
The bioactive ingredients and therapeutic effects of Marrubium vulgare - A review
}

Ali Esmail Al-Snafi 1, Hussein Ali Al-Saedy 2, Tayseer Ali Talab 1, Wajdi Jabbar Majid 3, Gaber El-Saber Batiha ${ }^{4}$, and Jafari-Sales Abolfazl 5

${ }^{1}$ Dept. of Pharmacology, College of Medicine, University of Thi qar, Iraq.

2 Dept. of Pharmaceutical Chemistry, College of Pharmacy, University of Thi qar, Iraq.

${ }^{3}$ Dept. of Biochemistry, College of Medicine, University of Thi qar, Iraq.

${ }^{4}$ Dept. of Pharmacology and Therapeutics, Faculty of Veterinary Medicines, Damanhour University, Egypt.

${ }^{5}$ Dept. of Microbiology School of Basic Sciences, Kazerun Branch, Islamic Azad University, Kazerun, Iran.

International Journal of Biological and Pharmaceutical Sciences Archive, 2021, 01(02), 009-021

Publication history: Received on 12 January 2021; revised on 01 February 2021; accepted on 03 February 2021

Article DOI: https://doi.org/10.30574/ijbpsa.2021.1.2.0301

\begin{abstract}
Marrubium vulgare (Family: Lamiaceae) was used traditionally in the treatment of dyspeptic complains, pulmonary infections, cough, rheumatoid arthritis, night blindness, loss of appetite, as cholagogue, purgative, diuretic, bitter tonic, carminative and appetizer. The phytochemical analysis revealed that the plant contained alkaloids, sterols, steroids, terpenoids (diterpene), saponins, flavonoid, catecholic tannins, anthocyans, phenolic compounds and many other bioactive ingredients. The pharmacological investigations showed that the plant exerted anti-inflammatory, antiedematogenic, analgesic, antioxidant, antimicrobial, antidiabetic, cardiovascular hypolipidemic, antispasmodic and many other biological effects. This review discussed the bioactive contents and pharmacological activities of Marrubium vulgare.
\end{abstract}

Keywords: Marrubium vulgare; metabolites; constituents; traditional uses; pharmacology; therapeutic; toxicity

\section{Introduction}

Plants generally produce many secondary metabolites which are bio-synthetically derived from primary metabolites and constitute an important source of chemicals which are used as pharmaceuticals, agrochemicals, flavours, fragrances, colours, biopesticides and food additives. Marrubium vulgare (Family: Lamiaceae) was used traditionally in the treatment of dyspeptic complains, pulmonary infections, cough, rheumatoid arthritis, night blindness, loss of appetite, as cholagogue, purgative, diuretic, bitter tonic, carminative and appetizer. The phytochemical analysis revealed that the plant contained alkaloids, sterols, steroids, terpenoids (diterpene), saponins, flavonoid, catecholic tannins, anthocyans, phenolic compounds and many other bioactive ingredients. The pharmacological investigations showed that the plant exerted anti-inflammatory, antiedematogenic, analgesic, antioxidant, antimicrobial, antidiabetic, cardiovascular hypolipidemic, antispasmodic and many other biological effects. This review will highlight the bioactive contents and pharmacological activities of Marrubium vulgare. The current review will highlight the bioactive contents and pharmacological activities of Marrubium vulgare.

\subsection{Synonyms}

Marrubium apulum, Marrubium ballotoides, Marrubium germanicum, Marrubium hamatum, Marrubium uncinatum, Marrubium vaillantii, Marrubium vulgare subsp. apulum, Marrubium vulgare var. apulum, Marrubium vulgare var.

\footnotetext{
${ }^{*}$ Corresponding author: Ali Esmail Al-Snafi; E mail: aboahmad61@yahoo.com

Dept of Pharmacology, College of Medicine, University of Thi qar.

Copyright $(2021$ Author(s) retain the copyright of this article. This article is published under the terms of the Creative Commons Attribution Liscense 4.0.
} 
caucasicum, Marrubium vulgare var. gossypinum, Marrubium vulgare var. lanatum, Marrubium vulgare var. microphyllum and Marrubium vulgare var. oligodon[1].

\subsection{Taxonomic classification}

Kingdom: Plantae, Subkingdom: Viridiplantae, Infrakingdom: Streptophyta, Superdivision: Embryophyta, Division: Tracheophyta, Subdivision: Spermatophytina, Class: Magnoliopsida, Superorder: Asteranae, Order: Lamiales, Family: Lamiaceae, Genus: Marrubium, Species: Marrubium vulgare [2].

\subsection{Common names}

Arabic: Hashishat Alkalib, Farasion Abiadh, Roubiya, Zekom, Ithn al-hemar, Ithn al-thawr; Chinese: ou xia zhi cao; English: Horehound, white horehound; French: marrube blanc, marrube vulgaire; German: Andorn; Hindi: Paharigandana; Portuguese: marroio; Persian: Faracion, Ghandnaye kohi, Shenar, Oftan-Sar, Korar; Russian: šandra obyknovennaja; Spanish: marrubio común; Swedish: kransborre [3-4].

\subsection{Distribution}

It is native to Africa (Algeria, Libya, Morocco and Tunisia), Asia (Armenia, Azerbaijan, Russian Federation- Ciscaucasia, China, Kazakhstan, Turkmenistan, Uzbekistan, Afghanistan, Iran, Iraq, Palestine, Jordan, Lebanon, Syria, Turkey and Pakistan), Europe (Belarus, Estonia, Latvia, Lithuania, Russian Federation-European part, Ukraine, Austria, Belgium, Czechoslovakia, Hungary, Netherlands, Poland, Switzerland, Denmark, Sweden, United Kingdom, Albania, Bulgaria, Former Yugoslavia, Greece, Italy, Romania, France, Portugal and Spain). It is naturalized in Africa (Cape Verde, Portugal - Azores, Lesotho and South Africa), Australasia (Australia and New Zealand), Northern America and Southern America and it is widely cultivated [3].

\subsection{Description}

Long-lived herbaceous plant usually growing 20-60 cm tall. Stems branched or unbranched. Leaves reduced upward; petiole 0.7-1.5 cm; leaf blade ovate to circular, $2-3.5 \times 1.8-3 \mathrm{~cm}$, adaxially polished, corrugate, and sparsely villous, abaxially densely scabrid strigose-villous, base broadly cuneate to rounded, margin dentate-serrate, apex obtuse to subrounded. Verticillasters axillary, many flowered, widely spaced basally, crowded upward, globose, $1.5-2.3 \mathrm{~cm}$ in diam.; bracts subulate, as long as to longer than calyx tube, reflexed. Calyx 10-veined, teeth 10, main 5 long, alternate with to 5 accessory teeth, 1-4 mm, subulate, hooked. Corolla white, ca. $9 \mathrm{~mm}$; tube ca. $6 \mathrm{~mm}$, densely pubescent outside, pilose annulate inside, upper lip as long as or slightly shorter than lower lip, straight or spreading, 2-lobed; middle lobe of lower lip reniform, undulate, 2-cleft. Nutlets triquetrous, ovoid, warty [5].

\subsection{Traditional uses}

Marrubium vulgare was used for dyspeptic complains and for loss of appetite. It also used as a choleretic or cholagogue herb [6].

Many Native American tribes extensively used the plant in formulations containing the leaves, or the leaves and flowers, for treatment of cough, mixed with honey because it is extremely bitter. Native Americans also used the root topically for rheumatoid arthritis [7]. In Mexico, the decoction of Marrubium vulgare was used in the traditional medicine for treatment of diabetes [8]. The herb was applied for the treatment of joint pain, inflammation, sore eyes, cough, bronchitis, pulmonary infections, cold and night blindness. The plant was also used to help in expulsion of fetus, as purgative, diuretic, bitter tonic, carminative and appetizer [9-10]. Marrubium vulgare raw material was recommended as a drink to accelerating the digestion processes [11].

\subsection{Physicochemical characteristics}

The petroleum ether, alcohol, and water extractive values of the whole herb were $2.77 \pm 0.3,8.66 \pm 1.2 \%$ and $5.90 \pm 0.8$ $\% \mathrm{w} / \mathrm{w}$ respectively. The ash value was $(10.7 \pm 0.46 \%)$ and water soluble ash value was $(8.9 \pm 0.65 \%)$ [9].

\subsection{Chemical constituents}

The preliminary phytochemical screening showed that the plant contained alkaloids, sterols, steroids, terpenoids (diterpene), saponins, flavonoid, catecholic tannins, anthocyans and phenolic compounds [9, 12-13].

The dried herb of Marrubium vulgare, contained 0.05\% essential oil [14]. The oil of Marrubium vulgare from Poland revealed the presence of 31 compounds. The main compounds identified in the essential oil of Marrubium vulgare were 
E-caryophyllene (34.51-36.78\%), germacrene D (22.45-27.18\%), bicyclogermacrene (9.54-11.12\%), $\delta$-amorphene (6.15-8.18\%), and carvacrol (4.71-6.64\%) [15-16].

Thirty two compounds were determined inMarrubium vulgare essential oil cultivated in Egypt. The GC/MS analysis revealed that carvacrol (36.28\%), followed by $\beta$-phellandrene $(15.49 \%)$ and carvyl acetate $(11.52 \%)$ were the main compounds of volatile oil extracted from Marrubium vulgare fresh herb. However, the isolated compounds were included (\%): $\beta$ - phellandrene 15.49, linalool 3.86, trans- sabinene hydrate 3.29, $\beta$-thujene 2.93, octen-3-ol 2.48, 1,8 cineol 1.49, $\alpha$-pinene 1.44, borneol 1.12, 1,8 -cineol 1.49, $\alpha$-pinene 1.44, borneol 1.12, camphore 0.64, camphene 0.64, terpinen-4-ol 0.97, sabinene $0.25, \alpha$-terpineol $0.33, \beta$-pinene 3.53, thymol 0.34 , octanol 0.16 , carvacrol 36.28, $\alpha$ phellandrene 0.60 trans-caryophyllene $4.06, \alpha$-terpinene $3.83, \alpha$-humulene 0.19 , carvyl acetate $11.52,(+)$ carvomenthene 0.30 , limonene 0.82 , $\alpha$-cubebene $0.47,7$-epi-sesquisabinene hydrate 0.27 , caryophyllene oxide 0.67 , cubenol $0.19,2,6$-dimethylheptadecane 0.18 , $\alpha$-copaene 0.22 , cis- sabinene hydrate 0.59 and E- $\beta$-farnesene $0.24 \%[17]$

The essential oils of Marrubium vulgare from Isfahan, Iran, contained 44 constituents, these included (\%): trans-2hexanal: 0.77 , heptanal: $4.26, \alpha$-thujene: 0.22 , $\alpha$-pinene: 6.64 , camphene: 0.36 , benzaldeyde: 0.19 , p-cymene: $4.76,-1,8$ cineole, 8.17, $-\Upsilon$ - terpinene: 2.62 , linalool: $0.43, \Upsilon$ - terpineol: 1.39 , decanal: 0.95 , carvone: 0.64 , piperitone: 2.11 , eugenol: 2.91 , a-copaene: $0.51, \beta$-cubebene: $1.08, \beta$-caryophyllene: 32.19 , geranyl linalool: 2.58 , (E)- $\beta$-farnesene: 11.39, a-humulene: 1.59 , alloaromadendrene: 0.97 , germacrene D: $0.41, \beta$-ionone: $1.16, \beta$-guaiene: 0.92 , $\alpha$-farnesene: 0.31 , a-muurolene: $0.23, \beta$-bisabolene: 0.81 , trans-calamenene: $0.64, \delta$-cadinene: $0.36, \alpha$-calacorene: 0.37 , spathulenol: 0.24 , caryophyllene oxide: 4.06 , viridiflorol: $0.28,-1,10$ di-epi-cubenol: 0.17 , epi- $\alpha$-cadinol: 0.25 , $\beta$-eudesmol: 0.19 , acadinol: $0.27, \beta$-cubebene: 0.18 , citronellyl butanoate: 0.39 , a-bisabolol: 0.19 , geranyltiglate: 0.18 , benzyl benzoate: 1.08 and cyclononasiloxane: $0.47 \%[18]$.

However, the hydrodistillation of the dried flowering aerial parts of Marrubium vulgare from the suburb of Nour, Mazandaran province, North of Iran, gave $0.4 \%(\mathrm{w} / \mathrm{w})$ light yellowish oil. The oil contained 8 sesquiterpenoids $(68.2 \%)$, 11 monoterpenoids (25.0\%), and one non-terpenoid (0.3\%). The compounds isolated from the oil of Marrubium vulgare were included (\%): $\alpha$-pinene 3.9, $\beta$-pinene: 4.8, $\delta$-3-carene: $2.2,1,8$-cineole: 4.1 , santolinyl acetate:0.7, nerol : 0.4 , ascaridole: 0.4 , cis-piperitone epoxide: 1.3 , trans-piperitone epoxide: 2.7 , isobornyl acetate: 4.2 , isoascaridole: 0.3 , $\alpha$-copaene: 3.8, 1-tetradecene: 0.3 , isocaryophyllene: 14.1 , germacrene D: 3.1, bicyclogermacrene: 3.4 , $\beta$-bisabolene: 20.4, $\alpha$-bisabolene: 2.9, $\delta$-amorphene: 1.4 and $\delta$-cadinene: $19.1 \%[19]$.

Analysis of oils of the aerial parts of Marrubium persicum from Varzeghan in East Azarbaijan province, Iran, showed that the essential oil of $M$. persicum contained a mixture of non-terpenoids $51.5 \%$, sesquiterpene hydrocarbons $27.9 \%$, monoterpene hydrocarbons $9 \%$, and oxygenated sesquiterpenes $4.8 \%$ and oxygenated monoterpenes $1.2 \%$. The constituents isolated from the essential oil were included (\%): n-nonane 1.6, benzaldehyde 0.9, $\alpha$-pinene 4.6, 1-octen3-ol 1.6, Sabinene 1.3, Myrcene 0.6, decane 0.2, $\alpha$-tolualdehyde 2.4, limonene 2.5, acetophenone 14.6, m-tolualdehyde 19.1 , o-tolualdehyde 3.5, nonanal 0.5, linalool 0.4, terpinen-4-ol 0.5, $\alpha$-terpineol $0.3, \alpha$-cubebene 0.3 , $\beta$-bourbonene 0.4 , $\beta$-caryophyllene 7.4, $\beta$-farnesene 6.1, $\alpha$-humulene 0.8 , germacrene D 10.5, bicyclogermacrene $1.3, \beta$-bisabolene $0.7, \delta$ cadinene 0.4 , spathulenol 0.5 , caryophyllene oxide $2.1, \alpha$-cadinol $0.5, \alpha$-bisabolol 1.7 , hexahydrofarnesyl acetone 2.9 , hexacosane 0.8 , octacosane 1.1 , nonacosane $2.3 \%[20]$.

While, the percent of essential oil obtained by hydrodistillation from aerial part of Marrubium vulgare collected from Zahedan and Kerman, south-eastern- Iran, was $0.34 \%$. Thirty four compounds were identified in the oil, the main isolated compounds were $\gamma$-eudesmol (11\%), germacrene (10\%), D- citronelly formate (10\%), $\beta$-citronellol $(8 \%)$, geranyl tiglate $(7.1 \%)$, geranyl formate $(6.02 \%)$, lendene $(5.15 \%)$, cyclononasiloxane- octadecamethyl $(4.3), 1,8$ cineole (3.75\%), geraniol (3.70\%), neryl acetate (3.41), $\gamma$ - cadinene (3.35) and $\beta$ - cubebene (3.30)[21].

However, the components isolated from the essential oils of the leaves of Marrubium vulgare from Almus-Tokat-Turkey, were included (\%): $\alpha$-pinene (28.85\%), $\beta$-pinene (18.31\%), $\beta$-phellandrene $(17.40 \%), 2$ - hexenal $(14.80 \%), \beta$-myrcene $(5.07 \%), \alpha$-phellandrene $(4.27 \%)$, caryophyllene $(3.86 \%), \alpha$-limonen $(3.88 \%)$, germacrene $(1.05 \%), \beta$-farnesene $(0.88 \%)$ and sabinen $(0.49 \%)[22]$.

Analysis of the essential oil from aerial parts of Marrubium vulgare from Algeria revealed that the total essential oils was $0.05 \%$, and the major constituents (\%) included 4,8,12,16-Tetramethyl heptadecan-4-olid (16.97), germacrene D-4-ol (9.61), $\alpha$ - pinéne (9.37), phytol (4.87), dehydro-sabina ketone (4.12), piperitone (3.27), $\delta$ - cadinene (3.13), 1 octen-3-ol (2.35) and benzaldehyde (2.31)[23]. 
While, analysis of the essential oils of the dried aerial parts of Tunisian Marrubium vulgare showed that the oils contained thirty five components. The major isolated compounds were: sesquiterpenes $(50.5 \%)$, $\beta$-bisabolene $(28.3$ $\%)$, $\beta$ - caryophyllene (7.8 \%), (E)- $\beta$-farnesene (7.4\%) and 1,8-cineole (4.8\%)[24].

However, the amount of the essential oil obtained by hydrodistillation from aerial part of Marrubium vulgare from the village of Ouled Mnasser in Sidi Bouzid, Tunisia, was $0.34 \%$. The oil composed of equal amounts of the oxygenated monoterpenes $(40.02 \%)$ and sesquiterpenes hydrocarbons (42.7\%). However, 34 compounds were isolated from the oil. $\Upsilon$-eudesmol (11.93\%), ledene (5.35\%), $\delta$-cadinene (3.30\%), transcaryophyllene $(2.15 \%), \beta$-bourbonene (1.96\%), $\alpha$-copaene $(1.37 \%), 1,8$ cineole $(3.72 \%)$, geranial $(2.74 \%)$ and $\alpha$-thujone $(2.29 \%)$ were the main isolated compounds[25].

Marruboside, 11-oxomarrubiin, marrubic acid, (+)(E)-caffeoyll-malic acid, acteoside, forsythoside B, arenarioside, ballotetroside, vulgarol, vulgarcoside A, $\beta$-sitosterol, lupeol, marrubiin, ladanein, vulgarin, apigenin -0-glucoside, luteolin, apigenin-7-lactates together with their 2"-0-glucuronides, 2"-0-0-glucosides, diosmetin, diosmetin-7glucoside, vitexin, vicenin II, luteolin 7-glucoside, luteolin-7-rhamnoside, luteolin-7-0- $\beta$-glucopyranoside, acacetin, acacetin-7-rhamnoside, apigenin-7-0- $\beta$ - glucopyranoside, apigenin-7-0-glucoside, apigenin-7-(6"'-p-coumaroyl] glucoside, 3-hydroxyapigenin-4'-0-(6"-0-p-coumaroyl)-beta-D-glucopyranoside, chrysoeriol, quercetin 3rhamnoglucoside and apigenin, stachydrine, ascorbic acid, caffeinic acid and tetrahydroisoquinoline alkaloids (emetine and cephaeline) were isolated from Marrubium vulgare[6,26-36].

The amount of marrubiin was calculated as $156 \mathrm{mg} / \mathrm{g}$ of the aerial parts of Marrubium vulgare extract [37]. The total phenolic contents of Marrubium vulgare leaves were 40.7-160 mg gallic acid equivalents/g and total flavonoids concentrations were 27.4- $66.3 \mathrm{mg}$ catechin equivalents/g [38]. While, the total phenolic and flavonoids in the aerial parts of Marrubium vulgare were $625 \mathrm{mg}$ gallic acid equivalent, and 1.62 g quercetin equivalent per $100 \mathrm{~g}$ of dried plant aerial parts respectively [39].

\section{Pharmacological effects}

\subsection{Anti-inflammatory and analgesic effects}

The anti-inflammatory effects of the methanolic extract of the aerial parts of Marrubium vulgare was evaluated in carrageenan- induced paw edema in rats. Marrubium vulgare methanolic extract (2.5, 5, $10 \mathrm{mg} / \mathrm{kg})$ alleviated paw inflammation as determined by reduction of paw thickness $(\mathrm{P}<0.001)$ as well as, myeloperoxidase activity $(\mathrm{P}<0.001)$, which was associated with a marked decrease in tissue edema [39].

The anti-inflammatory effect of the methanolic extract $(10,20$, and $40 \mathrm{mg} / \mathrm{kg} / 12 \mathrm{~h}$ ) of Marrubium vulgare, was studied in isoproterenol-induced myocardial infarction (MI) in rat model. Isoproterenol injection increased inflammatory response, as shown by a significant increase in peripheral neutrophil count, myocardial myeloperoxidase (MP0) activity and serum levels of creatinine kinase-MB (CK-MB) and TNF- $\alpha$ ( $\mathrm{p}<0.001)$. In the groups treated with 10, 20 and $40 \mathrm{mg} / \mathrm{kg}$ of Marrubium vulgare extract, serum CK-MB was subsided by $55.4 \%, 52.2 \%$ and 69\%, respectively. $40 \mathrm{mg} / \mathrm{kg}$ of the extract was significantly reduced MPO activity, TNF- $\alpha$ level and peripheral neutrophil $(\mathrm{P}<0.001)$ in MI group. Interstitial fibrosis was significantly attenuated in extract treated groups compared with control MI group [40].

Comounds: 11-oxomarrubiin, vulgarcoside $\mathrm{A}$ and 3-hydroxyapigenin-4'-0-(6"-0-p-coumaroyl]-beta-Dglucopyranoside isolated from whole Marrubium vulgare, exhibited moderate to low level of inhibition on nitric oxide production. Vulgarcoside A also showed a moderate inhibition on pro-inflammatory cytokine TNF- $\alpha$ [30].

Marrubiin, exhibited significant analgesic effect against the writhing test in mice. Marrubiinic acid showed better activity in experimental models of pain in mice [41].

The antinociceptive profile of marrubiin, was studied in some models of nociception in mice. Marrubiin exhibited potent and dose-related antinociceptive effects. ID50 was: $2.2 \mathrm{micromol} / \mathrm{kg}$, ip, in the writhing test, $6.6 \mathrm{micromol} / \mathrm{kg}$, ip, (first phase) and $6.3 \mathrm{micromol} / \mathrm{kg}$, ip, (second phase) in the formalin-induced pain test and $28.8 \mathrm{micromol} / \mathrm{kg}$, ip, in the capsaicin test [42].

The analgesic effects of the hydroalcoholic extract of Marrubium vulgare were investigated in different models of pain in mice. The extract exhibited significant analgesic activity and antagonizing chemically- induced acute pain, the effects which could be attributed to the presence of steroids and terpenes [43]. 


\subsection{Antioxidant effects}

The Antioxidant activity of the methanolic extract of the aerial parts of Marrubium vulgare was evaluated using DPPH radical scavenging assay and nitric oxide radical inhibition assay. The extract RC50 values for DPPH and nitric oxide antioxidant activity of the methanolic extract were $177 \mu \mathrm{g} / \mathrm{ml}$ and $370.5 \mu \mathrm{g} / \mathrm{ml} \mathrm{respectively} \mathrm{[39].}$

The alcoholic extract of Marrubium vulgare at concentrations of $(8,10 \mathrm{mg} / \mathrm{ml}$ ), and some isolated flavonoids (acacetin, apigenin, and acacetin-7-rhamnoside) showed high antioxidant activity towards scavenging of DPPH radical. The activity was corresponding to 88.2 standard ascorbic acid at concentration of $100 \mu \mathrm{M}$ [29].

The antioxidant potential of Marrubium vulgare essential oil was evaluated using scavenging of DPPH free radicals, $\beta$ carotene bleaching test and reducing power assay. The results showed that they possessed strong antioxidant activity [25].

The in vitro antioxidant assays was used to determine the ability of the compounds (luteolin-7-0- $\beta$-glucopyranoside, apigenin-7-0- $\beta$ - glucopyranoside, oleanolic acid, $\beta$-sitosterol, luteolin-7-0-rutinoside, and rosmarinic acid) isolated from the dried leaves of Marrubium vulgare, using MTT and LPO assays. Luteolin-7-0- $\beta$-glucopyranoside, apigenin-7-0$\beta$ - glucopyranoside, and luteolin-7-0-rutinoside showed the highest antioxidant activity. Apigenin-7-0- $\beta$ glucopyranoside possessed antioxidant activity similar to that of vitamin C. Luteolin-7-0-rutinoside showed the highest LPO inhibition by $89 \%$ at $100 \mu \mathrm{g} / \mathrm{ml}$ concentration. Oleanolic acid and $\beta$-sitosterol inhibited LPO by $24 \%$ and $40 \%$, respectively [28].

A strong radical scavenging activity was recorded for the methanol extract of Marrubium vulgare with $\mathrm{RC}_{50}$ value of $8.24 \mu \mathrm{g} / \mathrm{ml}$ [37]. The methanolic extract of Marrubium vulgare $(2.5-120 \mu \mathrm{g} / \mathrm{ml})$ showed antioxidant activity (EC 50 of $38.56 \pm 0.10 \mu \mathrm{g} / \mathrm{ml}$ ) with the using DPPH assay [44].

\subsection{Anticancer effects}

The in vitro anticancer activity of Marrubium vulgare alcoholic extract and some isolated flavonoids (acacetin, apigenin, and acacetin-7-rhamnoside) were tested against Ehrlich tumor cell lines and human tumor cell lines U251 and MCF7 (brain tumor and breast carcinoma cell lines, respectively). The alcoholic extract, acacetin, apigenin and acacetin-7rhamnoside possessed anticancer activity against against Ehrlich tumor cell lines and breast carcinom a MCF7 with $\mathrm{ED}_{50}<20 \mu \mathrm{g} / \mathrm{ml}$ [29]. The cytotoxic activity of aerial parts of Marrubium vulgare essential oil was studied against HeLa cell lines. Essential oil inhibited the proliferation of HeLa cell lines with IC 50 of $0.258 \mu \mathrm{g} / \mathrm{ml}[45]$.

Marrubium vulgare ethanolic extract dose-dependently reduced viability of melanoma (B16) and glioma (U251) cells, but not peripheral blood mononuclear cells. It arrested cell cycle in S + G2/M phase, associated with activation of MAP kinase p38 and up-regulation of antiproliferative genes p53, p21 and p27. Marrubium vulgare ethanolic extract also induced mitochondrial depolarization, activation of caspase- 9 and -3, Parp cleavage, phosphatidylserine exposure and DNA fragmentation. The mitochondrial apoptotic pathway was associated with the up-regulation of proapoptotic genes Pten, Bak1, Apaf1, and Puma and down-regulation of antiapoptotic genes survivin and Xiap. It also stimulated the expression of autophagy-related genes Atg5, Atg7, Atg12, Beclin-1, Gabarab and Sqstm1, as well as LC3-I conversion to the autophagosome associated LC3-II. The most abundant phenolic components of Marrubium vulgare ethanolic extract (ferulic, p-hydroxybenzoic, caffeic and chlorogenic acids), did not exert a profound effect on viability of tumor cells, suggesting that other components were responsible for its cytotoxicity [46].

Ladanein, a methoxylated flavones isolated from Marrubium vulgare, displayed moderate (20-40 microM) activities against K562, K562R (imatinib-resistant), and 697 human leukemia cell lines [26].

\subsection{Antimicrobial activities}

The antimicrobial activity of Marrubium vulgare extracts was studied against Pseudomonas aeruginosa, Staphylococcus aureus, Escherichia coli and Proteus vulgaris. Marrubium vulgare showed activity against Escherichia coli on the ethyl acetate phase, and on the diethyl ether and butanol phases against Pseudomonas aeruginosa. However, the three phases of the extracts showed no activity against Proteus vulgaris [13].

The antibacterial activity of Marrubium vulgare leave extracts were investigated against Enterobacter sp, S. aureus, E. coli, Acinetobacter baumanii, P. aeruginosa and S. epidermidi. The results revealed that the antibacterial activity possessed by the extract was varied according to the extract concentration and the species of pathogen. The MICs were $125-250 \mathrm{mg} / \mathrm{ml}[47]$. 
The antimicrobial activity of Marrubium vulgare flavonoids was evaluated against four bacterial strains pathogenic (Klebsiella pneumonia, Pseudomonas aeruginosa 7244, Escherichia coli 1429 and Staphylococcus aureus). The diameters of growth inhibition were 4 and $12 \mathrm{~mm}$ for Pseudomonas aeruginosa 7244, 0 to $14 \mathrm{~mm}$ for Staphylococcus aureus, on Mueller-Hinton medium, and 8-38 mm for Pseudomonas aeruginosa 7244 and between 0 to 6 mm for Staphylococcus aureus on Sabouraud medium[12].

Marrubium vulgare essential oil and ethanol extract were tested against 17 strains of $S$. aureus isolated from nose and throat sample from 160 healthy subjects. The ethanol extract and essential oil of Marrubium vulgare possessed growth inhibitory effect against most isolates. The least MIC value of ethanol extract of Marrubium vulgare was $2.5 \mathrm{mg} / \mathrm{ml}$ and the highest $\mathrm{MBC}$ values were 5 and $10 \mathrm{mg} / \mathrm{ml}[21]$.

The antimicrobial activity of aerial parts essential oil was studied against bacterial isolates (Staphylococcus aureus 1327, Staphylococcus epidermidis, Micrococcus luteus, Enterococcus faecalis, Enterobacter cloacae, Staphylococcus aureus 25923, Bacillus subtilis, Bacillus cereus, Pseudomonas aeruginosa 27853, Klebsielle pneumoniae WHO24 and Escherchia coli 25922), and fungal isolates (Botrytis cinerea, Fusarium solan, Penicillium digitatum and Aspergillus niger). Marrubium vulgare essential oil possessed significant activity against microorganisms especially Gram positive bacteria with inhibition zones and minimal inhibitory concentration values in the range of 6.6-25.2 mm and 1120-2600 $\mu \mathrm{g} / \mathrm{ml}$, respectively, whereas Gram negative bacteria exhibited high resistance. In antifungal study, Botrytis cinerea exhibited the highest sensitivity with inhibition zones of $12.6 \mathrm{~mm}$, while, Fusarium solani, Penicillium digitatum and Aspergillus niger were less sensitive to Marrubium vulgare essential oil [45].

The antibacterial activity of the methanolic extract of Marrubium vulgare whole plant (50,100, 200, $400 \mathrm{and} 600 \mathrm{mg} / \mathrm{ml}$ ) was tested by disc diffusion method against Escherichia coli, Bacillus subtilis, Staphylococcus aureus, S. epidermidis, Pseudomonos aeruginosa and Proteus vulgaris. The result revealed that the extract was very much effective against $B$. subtilis, S. epidermidis and S. aureus (zones of inhibition of 24,21 and $20 \mathrm{~mm}$ for $600 \mathrm{mg} / \mathrm{ml}$, respectively) and moderately effective against $P$. vulgaris and $E$. coli (zones of inhibition of 15 and $16 \mathrm{~mm}$ for $600 \mathrm{mg} / \mathrm{ml}$, respectively), while the extract was ineffective against $P$. aeruginosa [48].

Antimicrobial activity of methanol, acetone and ethyl acetate extracts from whole Marrubium peregrinum plant was investigated against 22 microorganisms including 15 bacterial strains (standard strains: Escherichia coli ATCC 25922, Staphylococcus aureus ATCC 25923, Enterococcus faecalis ATCC 29212, Pseudomonas aeruginosa ATCC 27853, Bacillus subtilis ATCC 6633, Bacillus pumilus NCTC 8241 and clinical strains: Escherichia coli, Staphylococcus aureus, Enterococcus faecalis, Pseudomonas aeruginosa, Proteus mirabilis, Sarcina lutea, Salmonella enterica, Bacillus subtilis and Bacillus cereus) and 7 fungal species [Aspergillus niger ATCC 16404, Penicillium italicum PMFKG-F29, Trichothecium roseum PMFKG-F32, Botrytis cinerea PMFKG-F33; Candida albicans (clinical isolate); Rhodotorula sp. PMFKG-F27 and Saccharomyces boulardii PMFKG-P34]. The strongest antimicrobial activity was detected against Gram positive bacteria while the activities on other species were moderate. The activity of tested extracts varied depending on the species and type and concentration of the extract. The comparative analyses showed that the most active was methanol extract (MIC from $0.3125 \mathrm{mg} / \mathrm{ml}$ to $40 \mathrm{mg} / \mathrm{ml}$ ) followed by ethyl acetate (MIC from $0.0781 \mathrm{mg} / \mathrm{ml}$ to $40 \mathrm{mg} / \mathrm{ml}$ ) and acetone extract (MIC from $0.1563 \mathrm{mg} / \mathrm{ml}$ to $40 \mathrm{mg} / \mathrm{ml}$ ). The most sensitive bacteria were Staphylococcus aureus ATCC 25923, Pseudomonas aeruginosa ATCC 27853 and Bacillus subtilis (MIC $0.0781 \mathrm{mg} / \mathrm{ml}$ ). The best antifungal extract was the methanol extract against Aspergillus niger ATCC 16404 (MIC: 0.625 mg/ml) [49].

\subsection{Antiparasitic and molluscicidal effects}

The anthelmintic activity of Marrubium vulgare aqueous and ethanolic leaves extracts $(0.78,1.55,3.1,6.2,12.5,25$, and $50 \mathrm{mg} / \mathrm{ml}$ ) was evaluated against digestive strongyles in naturally infected bovine using the egg hatch assay and larval mortality assay. The high effects were observed with $50 \mathrm{mg} / \mathrm{ml}$, but the lowest reduction on parasite eggs hatchability was observed in cultures exposed to $0.78 \mathrm{mg} / \mathrm{ml}$ of both extracts. Both aqueous and ethanolic extracts of Marrubium vulgare (at $50 \mathrm{mg} / \mathrm{ml}$ ) exhibited $45.8 \pm 1.99 \%$ and $51 \pm 2.53 \%$ larval mortality rate, respectively, at 24h [50].

Mortality of the 4th instar larvae of the mosquito Culex pipiens exposed to different doses of methanolic extract of Marrubium vulgare was varied with exposure time. The maximum mortalities $(31,40,59 \%)$ were recorded for the concentration of 200, 500 and $900 \mathrm{mg} / \mathrm{ml}$ respectively, after $72 \mathrm{~h}$ of exposure [51].

The molluscicidal activity of Marrubium vulgare essential oils was investigated in adult and eggs of Biomphalaria alexandrina. The $\mathrm{LC}_{50}$ and LC 90 of Marrubium vulgare essential oil against adult snails was 50 and $100 \mathrm{ppm} / 3 \mathrm{hrs}$, respectively. Moreover, Marrubium vulgare showed LC100 ovicidal activity at $200 \mathrm{ppm} / 24 \mathrm{hrs}$ [52]. 


\subsection{Antidiabetic effects}

The antidiabetic and antidyslipidemic effects of the methanolic extract of the aerial part of Marrubium vulgare were studied in streptozotocin- induced diabetic rats. Marrubium vulgare extract significantly reduced the blood glucose level from the second week. It also significantly increased plasma insulin and tissue glycogencontents. Furthermore, it also significant reduced plasma total cholesterol, triglycerides, and low density lipoprotein-cholesterol, and increased high density lipoprotein-cholesterol in diabetic rats [53].

A series in vivo experiments were carried out on albinos rats to determine the antidiabetic effects of the aqueous aerial part extract of Marrubium vulgare $(100,200$ and $300 \mathrm{mg} / \mathrm{kg} \mathrm{bw}$, twice a day, orally). The aqueous extract of the Marrubium vulgare [200 and $300 \mathrm{mg} / \mathrm{kg}$ bw] induced significant antidiabetic effect (decreased blood glucose by $50 \%$ for the dose $100 \mathrm{mg} / \mathrm{kg}$ and more than $60 \%$ for 200 and $300 \mathrm{mg} / \mathrm{kg}$ ) and antihyperlipidemic (dose-dependent effect). It significantly lowered the total lipids, triglycerides, and total cholesterol levels in treated animals, compared with diabetic controls group $(\mathrm{p}<0.001)$ [54].

The hypoglycemic effects of the acute administration of various ethanolic extracts (root, leaf and stem) of Marrubium vulgare were investigated in normoglycemic rats. Both extracts (root and stem) caused significant reductions of glycemia in healthy rat after intragastric administration of $100 \mathrm{mg} / \mathrm{kg}$. Furthermore, the orally administered ethanolic root extract suppressed the elevation in the serum glucose in oral glucose tolerance test [55].

The effects of Marrubium vulgare infusion in renal and liver function were studied in alloxan diabetic rats. Diabetic rats showed elevation of plasma creatinine, oxidative stress markers, in addition to renal and hepatic histological alteration. The treatment with Marrubium vulgare infusion attenuated blood glucose and creatinine, reduced oxidative stress and improved histopathological alterations [56].

The antidiabetic effect of the aqueous extract of Marrubium vulgare was studied in type 2 non-controlled diabetic patients. Patients received a prepared infusion of the dry leaves of the plant treatment for 21 days. Marrubium vulgaretreatment decreased the plasma glucose level by $0.64 \%$ and cholesterol and triglycerides by $4.16 \%$ and $5.78 \%$, respectively [57].

A randomized, double-blind, and controlled clinical trial was conducted to evaluate the clinical effect of the aqueous extract on type 2 non-controlled diabetes mellitus. The product consisted of fresh Marrubium vulgare leaves that were dried under environmental temperatures and protected from direct light and then milled. Patients had to prepare the treatment immediately before administration. Marrubium vulgare extract was administered three times a day, before every meal. The study was carried out for 21 days. Prior to infusion administration, every seven days and after the clinical trial, the fasting glucose, cholesterol, triglycerides, urea, creatinine, and uric acid in blood were determined. The effectiveness was considered as a decrease in the basal concentration of glucose, cholesterol, or triglycerides by at least $25 \%$. Marrubium vulgare caused that effect in only two of the 21 patients $(9.52 \%)$. The mean of plasma glucose level was reduced by $0.64 \%$, and that of cholesterol and triglycerides by $4.16 \%$ and $5.78 \%$, respectively [58].

\subsection{Hepatoprotective effect}

The hepatoprotective effect of the methanol extract of whole Marrubium vulgare was evaluated on paracetamol induced hepatotoxicity in rats. The hepatotoxic effects of paracetamol were significantly inhibited by the extract manifested by the restoration of serum biochemical parameters to near normal levels [59].

The antihepatotoxic activities of the active compounds of Marrubium vulgare were studied using $\mathrm{CCl}_{4}$ - induced hepatic toxicity in rats. Vulgarin exhibited a significant antihepatotoxic activity by reducing the elevated levels of serum enzymes such as serum glutamate oxaloacetate transaminase serum glutamate pyruvate oxaloacetate transaminase and alkaline phosphatase, while the total protein levels were increased compared with standard drug silymarin. These biochemical observations were also confirmed by recovery of damaged liver cells in histopathological examinations of the liver sections [60].

The hepatoprotective activity of aqueous extract of Marrubium vulgare (500 mg of dry leaves/kg/day, for 30 days) was studied in cyclophosphamide toxicity in rats. Elevation of alanine amino transferase, aspartate amino transferase, lactate dehydrogenase, and alkaline phosphatase and increased lipid peroxidation confirmed cyclophosphamideinduced liver toxicity. Cyclophosphamide also decreased the enzymatic defense system against oxidative stress. Marrubium vulgare extract attenuated cyclophosphamide-induced enzymes alteration and the associated liver damage. The protective effect of the plant was mainly attributed to the existence of phenolic acids and flavonoids and their antioxidant properties [61]. 
Marrubic acid (p-menthane-5,6-dihydroxy-3-carboxylic acid) isolated from the Marrubium vulgare, showed protective effects against hepatotoxicity induced by $\mathrm{CCl}_{4}$ in rats, by reducing the elevated levels of serum enzymes such as serum glutamate oxaloacetate transaminase by $40.16 \%$, serum glutamate pyruvate oxaloacetate transaminase by $35.06 \%$, and alkaline phosphatase by $30.51 \%[27]$.

The antihepatotoxic and antioxidant activities of Marrubium vulgare were studied against $\mathrm{CCl}_{4}$ - induced hepatic damage in rats. The extract was given orally in a dose of $500 \mathrm{mg} / \mathrm{kg} /$ day for 4 weeks along with $\mathrm{CCl}_{4}$ started at the 7 th week of induction of hepatotoxicity. The extract showed a significant antihepatotoxic effect by reducing the levels of AST, ALT and LDH significantly. However, ALP levels were decreased non-significantly. Furthermore, it exhibited significant antioxidant effects by increasing the GPx, GR and GST activities with increased GSH tissue contents and decreased production of MDA level. Furthermore, it alleviated histopathological changes in rats' liver treated with $\mathrm{CCl}_{4}[62$ ].

\subsection{Cardiovascular effects}

The cardioprotective effects of aqueous fraction of hydroalcoholic extract were studied in ischaemic- reperfused isolated rat hearts. Marrubium vulgare aqueous fraction $(40 \mu \mathrm{g} / \mathrm{ml})$ significantly decreased infarction size compared with control. All doses reduced the total ventricular ectopic beats during $30 \mathrm{~min}$ of ischaemia. The extract (40 $\mu \mathrm{g} / \mathrm{ml})$ decreased the arrhythmias during the first $30 \mathrm{~min}$ of reperfusion. The aqueous fraction scavenged DPPH radical with $\mathrm{RC}_{50}$ value of $47 \mu \mathrm{g} / \mathrm{ml}$. The total phenolic and flavonoids content of the fraction was $6.05 \mathrm{~g}$ gallic acid equivalent and $36.13 \mathrm{mg}$ quercetin equivalent per $100 \mathrm{~g}$ of dry plant material [63].

Severe myocardial necrosis with a sharp decline in the arterial blood pressure, left ventricular contractility, with marked increase in the left ventricular end-diastolic pressure were seen in the isoproterenol group. All pathological changes induced by isoproterenol were significantly improved by the Marrubium vulgare extract treatment. The authors concluded that the therapeutic effects of Marrubium vulgare attributed to its antioxidant activities [64].

Subcutaneous injection of rats with isoproterenol $(100 \mathrm{mg} / \mathrm{kg} /$ day, for 2 consecutive days) caused ST-segment elevation in ECG, left ventricular dysfunction, intensive myocardial fibrosis with a profound increase in myocardial myeloperoxidase (MPO) activity and serum levels of TNF- $\alpha$. All doses of the Marrubium vulgare extract significantly amended the ECG pattern and improved the left ventricular systolic pressure, contractility and relaxation $(\mathrm{P}<0.001)$. Interstitial fibrosis was significantly attenuated in treated groups compared with control MI group. Treatment with the extract also reduced serum levels of TNF- $\alpha$ (at least 40.35\%) and myocardial MPO activity (at least 30.47\%) [65].

The crude extracts of the aerial parts of Marrubium vulgare were strongly inhibited the in vitro KCl-induced contraction of rat aorta. It appeared that furanic labdane diterpenes, marrubenol and marrubiin were the most active compounds [66].

The relaxant activity of marrubenol (a diterpenoid extracted from Marrubium vulgare), and the underling mechanism were studied in rat aorta. Marrubenol inhibited the contraction evoked by $100 \mathrm{mM} \mathrm{KCl}\left(\mathrm{IC}_{50}: 11.8 \pm 0.3 \mathrm{microM}\right.$, maximum relaxation: $93 \pm 0.6 \%$ ) than of the contraction evoked by noradrenaline (maximum relaxation: $30 \pm 1.5 \%$ ) in rat aorta. It also simultaneously inhibited the Ca2+ signal and the contraction evoked by $100 \mathrm{mM} \mathrm{KCl}$, and decreased the quenching rate of fura-2 fluorescence by $\mathrm{Mn}^{2+}$. Marrubenol inhibited $\mathrm{Ba}^{2+}$ inward current in a voltage-dependent manner (KD: $8 \pm 2$ and $40 \pm 6$ microM at holding potentials of -50 and $-100 \mathrm{mV}$, respectively). The results revealed that Marrubenol inhibited smooth muscle contraction by blocking L-type calcium channels [67].

The hypotensive effect of the water extract of Marrubium vulgare was investigated in spontaneously hypertensive and in normotensive rats. Oral administration of Marrubium vulgare extract lowered the systolic blood pressure of spontaneously hypertensive rats but not in normotensive rats. Marrubium vulgare extract inhibited the contractile responses of rat aorta to noradrenaline and to $\mathrm{KCl}(100 \mathrm{mM})$. Inhibition was greater in aorta from spontaneously hypertensive rats compared to normotensive rats and was not affected by the NO synthase inhibitor, N-nitro-L-arginine [68].

The effects of 10 week- treatment with amlodipine or Marrubium vulgare water extract on systolic blood pressure, cardiovascular remodeling and vascular relaxation were studied in spontaneously hypertensive rats. Both treatments produced similar decrease in systolic blood pressure. Amlodipine treatment reduced left ventricle, aortic and mesenteric artery weight, while, marrubium treatment had a significant antihypertrophic effect in aorta only. Relaxation to acetylcholine (Ach) of mesenteric artery was improved by Marrubium vulgare but not by amlodipine treatment [69]. 


\subsection{Hypolipidemic effects}

The hypocholesterolemic and hypotriglyceridemic activities of four Marrubium vulgare herb extracts were evaluated using Triton WR-1339-induced hyperlipidemia in mice. After, 7 and $24 \mathrm{~h}$ intragastric administration of extracts, caused a significant decrease of plasma total cholesterol. Triglyceride levels were also significantly lowered by all extracts while petroleum ether extract produced the lowest decreasing level. Similar results were observed for LDL-cholesterol concentrations. Furthermore, the more polar extracts (methanol and ethyl acetate) showed a significant ameliorative action on elevated atherogenic index and LDL/HDL-C ratios, while these atherogenic markers were not statistically suppressed by the chloroform and petroleum ether extracts [70].

The aqueous extracts of Marrubium vulgare inhibited LDL oxidation and enhanced reverse cholesterol transport and can prevent cardiovascular diseases development. Incubation of LDL with the aqueous extracts of Marrubium vulgare significantly prolonged the lag phase $(\mathrm{P}=0.014)$, lowered the progression rate of lipid peroxidation $(\mathrm{P}=0.004)$, reduced the disappearance of electrophoretic mobility in a dose-dependent manner. Furthermore, incubation of HDL with the aqueous extracts significantly increased HDL-mediated cholesterol efflux from THP-1 macrophages implicating an independent ATP binding cassette A1 (ABCA1) pathways [71].

\subsection{Antiedematogenic effects}

The antiedematogenic profile of marrubiin, the main constituent of Marrubium vulgare, was studied in a model of microvascular leakage in mice ears. The results show that it exhibited significant and dose-related antiedematogenic effects. The ID 50 values (mg/kg, ip) and maximal inhibition (\%) for the different phlogistic agents were: histamine (13.84 $\mathrm{mg} / \mathrm{kg}$ and $73.7 \%$ ); bradykinin(18.82 $\mathrm{mg} / \mathrm{kg}$ and 70.0\%); carrageenan (13.61 $\mathrm{mg} / \mathrm{kg}$ and $63.0 \%)$. In other phlogistic agonists, such as prostaglandin E2, it caused inhibition of less than 50\%. Marrubiin (100 mg/kg) also significantly inhibited the Ovo-induced allergic edema in actively sensitized animals (maximal inhibition 67.6 $\pm 4 \%$ ) [72].

\subsection{Gastroprotective effect}

The gastroprotective effect of the methanol extract and marrubiin obtained from the leaves of Marrubium vulgare was studied using ethanol- and indomethacin- induced ulcers in mice. In ethanol-induced ulcers, the curative ratios were $49.31 \pm 0.57,74.31 \pm 0.91$ and $79.86 \pm 0.59 \%$ for the groups treated with 50 and $100 \mathrm{mg} / \mathrm{kg}$ of the extract and omeprazole, respectively. In indomethacin-induced ulcers, the percentages of ulcer inhibition were 50.32 $\pm 5.60,66.24 \pm 4.30$, $82.17 \pm 04.09$ and $67.52 \pm 4.38$, for the groups treated with 25, 50 and $100 \mathrm{mg} / \mathrm{kg}$ Marrubium vulgare extract and cimetidine, respectively. In both models, the marrubiin $(25 \mathrm{mg} / \mathrm{kg})$ significantly reduced all the parameters when compared with the control group $(\mathrm{P}<0.01)$. $\mathrm{pH}$ and mucus production were significantly increased in the groups treated with Marrubium vulgare extract and marubiin[73].

\subsection{Antispasmodic effects}

The antispasmodic effects of hydroalcoholic extract of the roots and aerial parts of Marrubium vulgare were evaluated in several smooth muscle preparations in vitro. The results showed that the extract possessed a significant antispasmodic activity, it inhibited the action of acetylcholine, bradykinin, prostaglandin E2, histamine and oxytocin, with putative selectivity for cholinergic contractions [74].

\section{Toxicity and side effects}

The rats given Marrubium vulgare at doses of 100,250,500, and $1000 \mathrm{mg} / \mathrm{kg}$ daily, for a period of 3 weeks and observed continuously for 3 weeks, showed no physical signs of toxicity such as writhing, gasping, palpitation and respiratory rate, or mortality[53].

The effects of ethanol-water (80:20) extract of Marrubium vulgare on the hematological parameters, macroscopic and histological aspects of the uterus and fetus in non-pregnant and pregnant rats were investigated. The results showed, a significant decrease on hematological parameters in normal rats and pregnant rats treated with the ethanol-water. Furthermore, the extract of Marrubium vulgare caused a significant decrease on the mean implantations of fetuses $(82.5 \%, \mathrm{P}<0.001)$ and their size $(47.2 \%, \mathrm{P}<0.01)$. However, the extract possessed no uterine histological change in nonpregnant treated rats, while, in pregnant rats, it induced severe histological change characterized by the existence of location of stopped gestation with lyses placental and embryo tissue. The results supported the abortifacient effect of Marrubium vulgare [75]. Extended use may lead to hypertension. While large doses can cause vomiting [76]. 


\section{Conclusion}

The current review discussed the chemical constituents, pharmacological effects and therapeutic importance of Marrubium vulgare as a promising medicinal plant with wide range of pharmacological activities which could be utilized in several medical applications because of its effectiveness and safety.

\section{Compliance with ethical standards}

\section{Acknowledgments}

We acknowledged the dean of Thi Qar College of medicine, the dean of Thi Qar College of pharmacy and the dean of Faculty of veterinary medicines for the scientific support.

\section{Disclosure of conflict of interest}

The authors confirm that this paper's content has no conflict of interests.

\section{References}

[1] The plant list, Marrubium vulgare, http://www.theplantlist. org/tpl1.1/ record/kew-120952

[2] Al-Snafi A. Encyclopedia of chemical constituents and pharmacological effects of Iraqi medicinal plants. Rigi Pubication, 2015.

[3] U.S. National plant germplasm system, Marrubium vulgare, https://npgsweb. ars-grin.gov/gringlobal/ taxonomydetail.aspx?23450

[4] Ahvazi M, Balali GR, Jamzad Z and Saeidi H. A taxonomical, morphological and pharmacological review of Marrubium vulgare L., an old medicinal plant in Iran. Journal of Medicinal Plants 2018; 17(65):7-24.

[5] Flora of China, Marrubium vulgare, http://www.efloras.org/florataxon.aspx? flora_id=2\&taxon_id=200019796

[6] Capasso, Francesco, et al. Phytotherapy: A quick reference to herbal medicine. Berlin, Heidelberg: Springer Berlin Heidelberg 2003.

[7] Moerman, Daniel E. Native American ethnobotany. Portland, Timber Press 2010.

[8] Castillo-España P and Monroy-Ortiz C. Plantas Medicinales Utilizadas en el Estado de Morelos. $2^{\text {nd }}$ ed. Cuernavaca: Universidad Autónoma del Estado de Morelos, 2000.

[9] Mittal V and Nanda A. The pharmacognostical evaluation of the Marrubium vulgare Linn collected from the Pulwama district of Jammu and Kashmir state in India. Journal of Chemical and Pharmaceutical Research 2016; 8(10):7-15.

[10] Kirtikar KR and Basu BD. Indian medicinal plants. International Book Distributors, Dehradun, India, 1996: 2007 2009.

[11] Pietroni A, Quave C, Nebel S and Heinrich M. Ethnopharmacy of the ethnic Albanians (Arbëreshë) of northern Basilicata, Italy. Fitoterapia 2002; 73(3): 217-241.

[12] Djahra AB, Bordjiba O, Benkherara S and Benkaddour M. Evaluation of Algerian spontaneous species: phytochemical and biological study of aromatic and medicinal plant Marrubium vulgare. Phyto Chem \& Bio Sub Journal 2015; 9(1): 2-9.

[13] Kahlouche-Riachi F, Djerrou Z, Ghoribi L, Djaalab I, Mansour-Djaalab H, Bensari C and Hamdi-Pacha Y. Chemical characterization and antibacterial activity of phases obtained from extracts of Artemisia herba alba, Marrubium vulgare and Pinus pinaster. International Journal of Pharmacognosy and Phytochemical Research 2015; 7(2):270274.

[14] Zawiślak G. Cropping evaluation of white horehound (Marrubium vulgare L.), grown from sowing and seeding. Herba Pol 2009; 55(3):63-68.

[15] Zawiślak G. Comparison of chemical composition of the essential oil from Marrubium vulgare L. and M. incanum Desr. during the second year of cultivation. Acta Agrobot 2015; 68(1):59-62. 
[16] Zawiślak G. Chemical composition of essentials oils of Marrubium vulgare L. and Marrubium incanum Desr. grown in Poland. Chemija 2012; 23(2):136-140.

[17] Said-Al Ahl HAH, Gendy ASH, Mahmoud AA and Mohamed HFY. Essential oil composition of Marrubium vulgare L cultivated in Egypt. International Journal of Plant Science and Ecology 2015; 1(4):138-141.

[18] Golparvar AR, Hadipanah A, Mehrabi AM and Armin A. Essential oil composition of Marrubium vulgare L from Iran. Journal of Herbal Drugs 2015; 6(1):1-5.

[19] Morteza-Semnani K. The essential oil composition of Marrubium vulgare L from Iran. Journal of Essential Oil Research 2008; 20:488-490.

[20] Hamedeyazdan S, Fathiazad F and Asnaashari S. Chemical composition of the essential oil from Marrubium persicum C. A. Mey. (Lamiaceae). Pharmaceutical Sciences 2013; 19(2):35-38.

[21] Bokaeian M, Saboori E, Saeidi S, Niazi AA, Amini-Borojeni N, Khaje H and Bazi S. Phytochemical analysis, antibacterial activity of Marrubium vulgare L against Staphylococcus aureusin vitro. Zahedan Journal of Research in Medical Sciences 2014; 16 (10): 60-64.

[22] Bayir B, Gunduz H, Usta T, Sahin E, Ozdemir Z, Kayir O, Sen O, Aksit H, Elmastas M and Erenler R. Chemical composition of essential oil from Marrubium vulgare L leaves. Journal of New Results in Science 2014; 6:44-50.

[23] Abadi A and Hassani A. Chemical composition of Marrubium vulgare L essential oil from Algeria. International Letters of Chemistry, Physics and Astronomy 2013; 8(3):210-214.

[24] Hamdaoui B, Aidi Wannes W, Marrakchi M, Ben Brahim N and Marzouk B. Essential oil composition of two Tunisian horehound species: Marrubium vulgare L and Marrubium aschersonii Magnus. Journal of essential oilbearing plants JEOP 2013; 16(5):608-612.

[25] Kadri A, Zarai Z, Békir A, Gharsallah N, Damak M and Gdoura R. Chemical composition and antioxidant activity of Marrubium vulgare L essential oil from Tunisia. African Journal of Biotechnology 2011; 10(19): 3908-3914.

[26] Alkhatib R, Joha S, Cheok M, Roumy V, Idziorek T, Preudhomme C, Quesnel B, Sahpaz S and Bailleul Fand Hennebelle T. Activity of ladanein on leukemia cell lines and its occurrence in Marrubium vulgare.Planta Med 2010; 76(1):86-87.

[27] Ahmed B, Masoodi MH, Siddique AH and Khan S. A new monoterpene acid fromMarrubium vulgare with potential antihepatotoxic activity.Nat Prod Res 2010; 24(18):1671-1680.

[28] Neamah SI, Sarhan IA and Al-Shaye'a ON. Bioactive compounds from Marrubium vulgare L based on in vitro antioxidant activity. Journal of Global Pharma Technology 2017; 11(09):183-188.

[29] Mohamed NH and Atta EM. Cytotoxic and antioxidant activity of Marrubium vulgare and its flavonoid constituents. $2^{\text {nd }}$ International Conference on Chemical, Environmental and Biological Sciences, Dubai (UAE), March 2013; 17-18,

[30] Shaheen F, Rasoola S, Shah ZA, Soomro S, Jabeen A, Mesaik MA and Choudhary MI. Chemical constituents of Marrubium vulgare as potential inhibitors of nitric oxide and respiratory burst.Nat Prod Commun 2014; 9(7): 903-906.

[31] Sahpaz S, Garback N, Tits M and Bailleul F. Isolation and pharmacological activity of phenylpropanoid esters from Marrubium vulgare. J Ethnopharmacol2002; 79(3):389-392.

[32] Sahpaz S, Hennebelle T and Bailleul F. Marruboside, a new phenylethanoid glycoside from Marrubium vulgare L.Nat Prod Lett 2002;16(3):195-199.

[33] Amer MMA. Constituents of the arial parts of Marrubium vulgare L. Mansoura J Pharma Sci 1993; 9(1): 92-98.

[34] Nawwar Mahmoud AM, El-Mousallamy Amany MD, Barakat HH, Buddrus J and Linscheid M. Flavonoid lactates from leaves of Marrubium vulgare. Phytochemistry 1989; 28(11):3201-3206.

[35] Pulatova TP and Khalmatov KK. Chemical study of Marrubium vulgare. Tashkent. Farmatsevt Inst 1966; 4:32-35.

[36] Knöss W and Zapp J. Accumulation of furanic labdane diterpenes in Marrubium vulgare and Leonurus cardiaca.Planta Med 1998; 64(4):357-361.

[37] Yousefi K, Hamedeyazdan S, Torbati M and Fathiazad F. Chromatographic fingerprint analysis of marrubiin in Marrubium vulgare L via HPTLC technique.Adv Pharm Bull 2016; 6(1):131-136. 
[38] Bouterfas K, Mehdadi Z, Elaoufi MM, Latreche A and Benchiha W. Antioxidant activity and total phenolic and flavonoids content variations of leaves extracts of white Horehound (Marrubium vulgare Linné) from three geographical origins. Ann Pharm Fr 2016;74(6):453-462.

[39] Fathiazad F, Rameshrad M, Asghari S, Hamedeyazdan S, Garjani A and Maleki-Dizaji N. Phytochemical screening and anti-inflammatory effect of Marrubium vulgare L methanol extract on carrageenan- induced paw inflammation in rats. Pharmaceutical Sciences 2017; 23:3-11.

[40] Yousefi K, Fathiazad F, Soraya H, Rameshrad M, Maleki-Dizaji N and Garjani A. Marrubium vulgare L methanolic extract inhibits inflammatory response and prevents cardiomyocyte fibrosis in isoproterenol- induced acute myocardial infarction in rats.Bioimpacts 2014; 4(1):21-27.

[41] Meyre-Silva C, Yunes RA, Schlemper V, Campos-Buzzi F and Cechinel-Filho V. Analgesic potential of marrubiin derivatives, a bioactive diterpene present in Marrubium vulgare (Lamiaceae). Farmaco 2005; 60(4):321-326.

[42] De Jesus RA, Cechinel-Filho V, Oliveira AE and Schlemper V. Analysis of the antinociceptive properties of marrubiin isolated from Marrubium vulgare.Phytomedicine 2000;7(2):111-115.

[43] De Souza MM, De Jesus RA, Cechinel-Filho V and Schlemper V. Analgesic profile of hydroalcoholic extract obtained from Marrubium vulgare.Phytomedicine 1998; 5(2):103-107.

[44] Amri B, Martino E, Vitulo F, Corana F, Kaâb LB, Rui M, Rossi D, Mori M, Rossi S and Collina S. Marrubium vulgare L leave extract: Phytochemical composition, antioxidant and wound healing properties. Molecules 2017; 22(11). pii: E1851.

[45] Zarai Z, Kadri A, Chobba IB, Mansour RB, Bekir A, Mejdoub H and Gharsallah N. The in vitro evaluation of antibacterial, antifungal and cytotoxic properties of Marrubium vulgare L essential oil grown in Tunisia. Lipids in Health and Disease 2011; 10(161):1-8.

[46] Paunovic V, Kosic M, Djordjevic S, Zugic A, Djalinac N, Gasic U, Trajkovic V and Harhaji-Trajkovic J. Marrubium vulgare ethanolic extract induces proliferation block, apoptosis, and cytoprotective autophagy in cancer cells in vitro.Cell Mol Biol (Noisy-le-grand) 2016; 62(11):108-114.

[47] Larbi K, Kaf A, Nahnouh N and Tir Touilmeddah A. Thein vitro evaluation of antibacterial effect of Marrubium vulgare L leaf extract grown in Algeria. Current Research on Biological Sciences 2016; 1(1):13-20.

[48] Masoodi MH, Ahmed B, Zargar IM, Khan SA, Khan S and Singh P. Antibacterial activity of whole plant extract of Marrubium vulgare. African Journal of Biotechnology 2008; 7 (2):86-87.

[49] Radojević I, Stanković M, Stefanović O, Čomić L, Topuzović M, Vasić S and NikolićM. Exploring antimicrobial activity of Horehound, Marrubium peregrinum L extracts. Kragujevac J Sci 2013; 35:99-106.

[50] Moussouni L, Benhanifia M and Ayad A. In vitro anthelmintic effects of aqueous and ethanolic extracts of Marrubium vulgare leaves against bovine digestive strongyles. Turkiye Parazitol Derg 2018; 42(4):262-267.

[51] Amel A and Selima B. Larvicidal effect of Marrubium vulgare on Culexpipiens in eastern Algeria. Energy Procedia 2015; 74:1026-1031.

[52] Salama MM, Taher EE, El-Bahy MM. Molluscicidal and mosquitocidal activities of the essential oils of Thymus capitatus Hoff et Link and Marrubium vulgare L. Rev Inst Med Trop Sao Paulo. 2012; 54(5):281-286.

[53] Elberry AA, Harraz FM, Ghareib SA, Gabr SA, Nagy AA and Abdel-Sattar E. Methanolic extract of Marrubium vulgare ameliorates hyperglycemia and dyslipidemia in streptozotocin- induced diabetic rats. International Journal of Diabetes Mellitus 2015; 3:37-44.

[54] Boudjelal A, Henchiri C, Siracusa L, Sari M and Ruberto G. Compositional analysis and in vivo anti-diabetic activity of wild Algerian Marrubium vulgare L infusion. Fitoterapia 2012; 83(2):286-292.

[55] Vergara-Galicia J, Aguirre-Crespo F, Tun-Suarez A, Crespo AA, Estrada-Carrillo M, Jaimes-Huerta I, Flores-Flores A, Estrada-Soto S and Ortiz-Andrade R. Acute hypoglycemic effect of ethanolic extracts from Marrubium vulgare. Phytopharmacology 2012; 3(1):54-60.

[56] Ghlissi Z, Atheymen R, Sahnoun Z, Zeghal K, Mnif H and Hakim A. The effect ofMarrubium vulgare L on hyperglycemia-mediated oxidative damage in the hepatic and renal tissues of diabetic rats. International Journal of Pharma and Chemical Research 2015; 1(2):97-106. 
[57] Herrera-Arellano A, Aguilar-Santamaría L, García-Hernández B, Nicasio-Torres P and Tortoriello J. Clinical trial of Cecropia obtusifolia and Marrubium vulgare leaf extracts on blood glucose and serum lipids in type 2 diabetics. Phytomedicine 2004; 11(7-8): 561-566.

[58] Villanueva JR, ID Esteban JM and Villanueva LR. A reassessment of the Marrubium vulgare L herb's potential role in diabetes mellitus type 2: First results guide the investigation toward new horizons. Medicines 2017; 4: 57.

[59] Akther N, Shawl AS, Sultana S, Chandan BK and Akhter M. Hepatoprotective activity of Marrubium vulgare against paracetamol induced toxicity. Journal of Pharmacy Res 2013; 7:565-570.

[60] Verma A, Masoodi M and Ahmed B. Lead finding from whole plant of Marrubium vulgareL with hepatoprotective potentials through in silico methods. Asian Pacific Journal of Tropical Biomedicine 2012;S1308-S1311.

[61] Ettaya A, Dhibi S, Samout N, Elfeki A and Hfaiedh N. Hepatoprotective activity of white horehound (Marrubium vulgare) extract against cyclophosphamide toxicity in male rats.Can J Physiol Pharmacol 2016; 94(4):441-447.

[62] Elberry AA, Harraz FM, Ghareib SA, Nagy AA, Gabr SA, Suliaman MI and Abdel-Sattar E. Antihepatotoxic effect of Marrubium vulgare and Withania somnifera extracts on carbon tetrachloride-induced hepatotoxicity in rats.J Basic Clin Pharm 2010;1(4): 247-254.

[63] Garjani A, Tila D, Hamedeyazdan S, Vaez H, Rameshrad M, Pashaii M and Fathiazad F. An investigation on cardioprotective potential of Marrubium vulgare aqueous fraction against ischaemia-reperfusion injury in isolated rat heart.Folia Morphol (Warsz) 2017; 76(3):361-371.

[64] Yousefi K, Soraya H, Fathiazad F, Khorrami A, Hamedeyazdan S, Maleki-Dizaji N and Garjani A. Cardioprotective effect of methanolic extract of Marrubium vulgare $\mathrm{L}$ on isoproterenol-induced acute myocardial infarction in rats. Indian J Exp Biol 2013; 51(8):653-660.

[65] Rameshrad M, Yousefi K, Fathiazad F, Soraya H, Hamedeyazdan S, Khorrami A, Maleki-Dizaji N and Garjani A. A methanolic extract of Marrubium vulgare $\mathrm{L}$ suppresses inflammatory responses in isoproterenol induced myocardial infarction in rat. Research in Pharmaceutical Sciences 2012; 7(5):S959.

[66] El Bardai S, Morel N, Wibo M, Fabre N, Llabres G, Lyoussi B and Quetin-Leclercq J. The vasorelaxant activity of marrubenol and marrubiin from Marrubium vulgare.Planta Med 2003; 69(1):75-77.

[67] El-Bardai S, Wibo M, Hamaide MC, Lyoussi B, Quetin-Leclercq J and Morel N. Characterisation of marrubenol, a diterpene extracted from Marrubium vulgare, as an L-type calcium channel blocker. Br J Pharmacol 2003; 140(7):1211-1216.

[68] El Bardai S, Lyoussi B, Wibo M and Morel N. Pharmacological evidence of hypotensive activity of Marrubium vulgare and Foeniculum vulgare in spontaneously hypertensive rat.Clin Exp Hypertens 2001; 23(4):329-343.

[69] El Bardai S, Lyoussi B, Wibo M and Morel N. Comparative study of the antihypertensive activity of Marrubium vulgare and of the dihydropyridine calcium antagonist amlodipine in spontaneously hypertensive rat.Clin Exp Hypertens 2004; 26(6):465-474.

[70] Ibrahim AY, Hendawy SF, Elsayed AA and Omer EA. Evaluation of hypolipidemic Marrubium vulgare effect in Triton WR-1339-induced hyperlipidemia in mice.Asian Pac J Trop Med 2016; 9(5):453-459.

[71] Berrougui $\mathrm{H}$, Isabelle $\mathrm{M}$, Cherki $\mathrm{M}$ and Khalil A. Marrubium vulgare extract inhibits human-LDL oxidation and enhances HDL-mediated cholesterol efflux in THP-1 macrophage. Life Sci 2006; 80(2):105-112.

[72] Stulzer HK, Tagliari MP, Zampirolo JA, Cechinel-Filho V and Schlemper V. Antioedematogenic effect of marrubiin obtained from Marrubium vulgare.J Ethnopharmacol 2006; 108(3):379-384.

[73] Paula de Oliveira A, Santin JR, Lemos M, Klein Júnior LC, Couto AG, Meyre da Silva Bittencourt C, Filho VC and Faloni de Andrade S. Gastroprotective activity of methanol extract and marrubiin obtained from leaves of Marrubium vulga (Lamiaceae). J Pharm Pharmacol 2011; 63(9):1230-1237.

[74] Schlemper V, Ribas A, Nicolau M and Cechinel Filho V. Antispasmodic effects of hydroalcoholic extract of Marrubium vulgare on isolated tissues.Phytomedicine 1996; 3(2):211-216.

[75] Aouni R, Ben Attia M, Jaafoura MH, Bibi-Derbel A and Haouari M. Effects of the hydro-ethanolic extract of Marrubium vulgare in female rats.Asian Pac J Trop Med 2017; 10(2):160-164.

[76] Pursell JJ. The herbal apothecary: 100 medicinal herbs and how to use them. Portland, Oregon: Timber Press 2016; 112-113 